\title{
Economic evaluation of mitigation methods against voltage dips and interruptions based on stochastic reliability
}

\author{
Dirk Van Hertem*, Marcel Didden ${ }^{\dagger}$, Johan Driesen*, Ronnie Belmans* \\ * Departement ESAT/ELECTA \\ Katholieke Universiteit Leuven \\ Kasteelpark 10, B-3001 Heverlee \\ e-mail: dirk.vanhertem@ieee.org \\ $\dagger$ Electrical Power Systems and Metrology \\ Laborelec \\ Rodestraat 125, B-1630 Linkebeek \\ e-mail: marcel.didden@laborelec.com
}

\begin{abstract}
This article describes a method to select the technoeconomic optimal method for the mitigation of voltage dips and interruptions. Because of the wide variety in mitigation equipment available on the market, the uncertainty of the grid reliability and the mostly unknown interruption cost, it is a very difficult task to determine which investment is the 'optimal' one for a certain location. One of the most challenging issues in finding this optimal solution, is comparing totally different protection methods, each with their degree of protection, and their specific costs. The theoretical approach is considered and the difficulties which make it impractical for use are stated. Also the used investment policy in the industries is briefly treated, based on performed surveys. Next a method is proposed to compare different mitigation methods, avoiding the drawbacks of the theoretical method, based on the reliability indices of the power supply. The influence of the grid reliability is discussed. This method is based on the stochastic character of the electricity distribution reliability.
\end{abstract}

\section{Key Words}

Power Quality economics, voltage dips, voltage interruptions, mitigation, economics of reliability

\section{Introduction}

\section{A. Consequences of interruptions and dips}

Electricity is often regarded as being always available. This perception of electricity distribution being a trivial matter is clearly incorrect, as recent blackouts in the United States and Italy have shown. These major blackouts caused a rising in the number of conferences and publications from within the power engineer- ing world (e.g. $[1,2]$ ), but also the worldwide media covered these events and brought the human dependence on electricity to the attention. But not only large newsbreaking blackouts threaten the normal electricity supply. Small scale, local voltage interruptions and even voltage dips have comparable consequences for the affected electricity consumers. These small-scale events occur frequently (see also 2-B.) and cost the economy millions of Euros a year [3]. This damage caused by interruptions can be calculated as the simple multiplication of the average cost of a process interruption and the number of process interruptions. The process interruption cost consists not only of the loss of production, but also includes loss of data, loss of market, loss of client thrust, loss of comfort, additional costs to comply with existing contracts,...

\section{Number of process interruptions}

One of the crucial parameters in determining the overall cost caused by voltage interruptions and dips, is the average number of events that the sensitive equipment faces every year. This number depends on grid reliability at the connection point, the on-site generation and propagation of voltage interruptions and dips (including the effect of mitigation equipment) and the sensitivity of the installation to these voltage fluctuations.

\section{A. Sensitivity to voltage dips and interruptions}

Each device or process has its own characteristic immunity against voltage dips and interruptions. It can be assumed that all voltage interruptions cause an interruption of the normal working of sensitive equipment without protection. For voltage dips, this is not the case: each installation has its own voltage tolerance characteristics as a function of dip duration and depth. This is illustrated in fig. 1 for computers. The voltage tolerance 


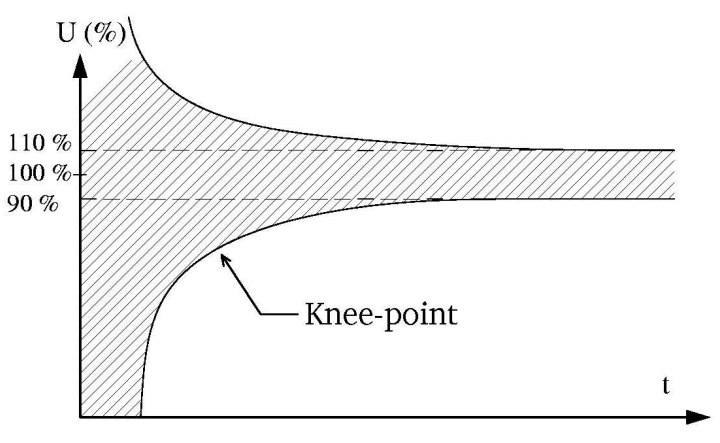

Figure 1: The voltage tolerance of an installation is dependent on dip duration and dip depth. The shaded area covers the harmless voltage dips.

Table 1: Range of voltage tolerances (knee-point) of frequently used sensitive equipment [4]. The voltages in this table are the voltage depths in percent of the nominal

\begin{tabular}{|l|rr|rr|rr|}
\cline { 2 - 7 } \multicolumn{1}{c|}{} & \multicolumn{4}{c|}{ Voltage } \\
\cline { 2 - 7 } \multicolumn{1}{c|}{} & sensitive & \multicolumn{1}{c|}{ normal } & insensitive \\
\hline & ms & U\% & ms & U\% & ms & U\% \\
\hline PLC & 20 & 25 & 260 & 40 & 620 & 55 \\
PLC input card & 20 & 20 & 40 & 45 & 40 & 70 \\
3,7 kW VSD & 30 & 20 & 50 & 25 & 80 & 40 \\
AC control relays & 10 & 25 & 20 & 35 & 30 & 40 \\
Motor Starter & 20 & 40 & 50 & 50 & 80 & 60 \\
PC & 30 & 20 & 50 & 40 & 70 & 50 \\
\hline
\end{tabular}

of different devices is delivered by the manufacturer, can be found in literature or needs to be determined through tests. Table 1 provides the knee-point (assuming a rectangular shaped characteristic) in the voltage tolerance characteristic of some frequently installed equipment. Probably the most important group of sensitive equipment is formed by computer applications, or more general, applications fed through a switched-mode power supply (SMPS). For these applications, the $\mathrm{ITIC}^{1}$ has issued a characteristic which reflects the voltage tolerance that typically can be tolerated by Information Technology Equipment (ITE). This curve replaces the former, well-known CBEMA $^{2}$-curve. When determining the actual number of interruptions encountered by a larger set of sensitive equipment from different manufacturers (e.g. a typical IT center), this curve can be used as the voltage tolerance curve of the installation. Measurement data have shown that applications which comply with the voltage tolerance characteristics of the ITIC [5] are only influenced by less than one third of the voltage dips measured [6].

The number of actual interruptions the sensitive installation encounters on a yearly basis, is the sum of the number of interruptions and the number of dips outside the tolerance of the equipment.

The distribution of the voltage dips $(\bar{\delta})$, as a function of dip duration $\left(\Delta t_{\text {dip }}\right)$ and remaining voltage $\left(U_{\text {rem }}\right)$,

\footnotetext{
${ }^{1}$ Information Technology Industry Council, http://www. itic . org/ [5] tion
}

determines the number of process interruptions, caused by voltage dips.

A representation of a typical cumulative voltage dip distribution is shown in fig. 2. Such a dip distribution can be obtained by using historical data, contacting the local grid maintainer or through detailed measurement (preferably at a number of different locations in the grid to reduce measuring period and increase accuracy [7]). Considering only the actual number of voltage dips, without making a distinction in depth and duration, simplifies and shortens the measurements significantly, but the voltage dip distribution has to be obtained from nearby sites.

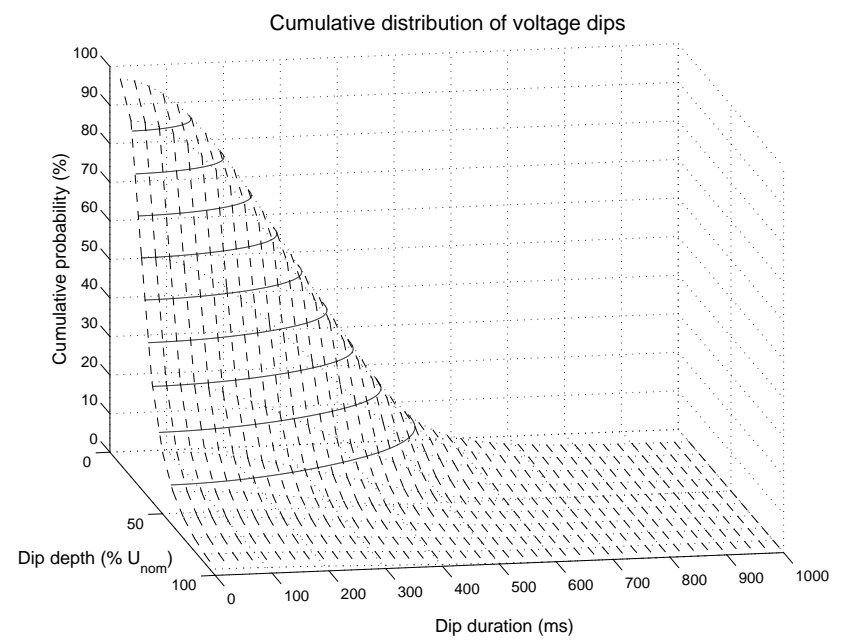

Figure 2: Typical cumulative distribution of voltage dips on a MV site. This curve represents the possibility that a voltage dip with a larger $\Delta t_{d i p}$ and $U_{\text {rem }}$ occurs. Only events with a dip depth larger then $10 \%$ are considered (as in most standards).

\section{B. Network reliability}

The mitigation of voltage dips and interruptions is often referred to, or considered as, the reduction of the number of such events below a certain level. However, in practice a mitigation method does not mitigate until a certain level of reliability is reached, but it will mitigate a certain fraction, percentage of the events. This means that the actual number of process interruptions strongly relies on the number of occurring events on the grid.

The variables that have to be taken into account concerning the grid reliability are the average number of long interruptions per year $(\lambda)$, the average interruption duration (also called MTTR, Mean Time To Repair) and the voltage dips that occur. For the calculations needed, it can be assumed that the MTTR and $1 / \lambda$ are exponential distributed [4]. The inverse of $\lambda$ is often referred to as the MTBF (Mean Time Between Failures): $8760 / \lambda=M T B F[h]$. The value of $\lambda$ is strongly dependent on the location of the connection point. For instance LV/MV substations directly coupled (\#1 in fig. 3) to the HV substation in Western Europe experience about $\lambda=0,1$ interruptions/year, 
with an expected $M T T R=60$ min, while those who are connected in an open ring structure (\#2 in fig. 3) experience between $\lambda=0,3$ and 1,8 interruptions/year (average of 0,9 ) and repair times between 60 and $100 \mathrm{~min}$ (average of $80 \mathrm{~min}$ ) [6,8]. Other publications offer results for other voltage levels (e.g. $[9,10]$ ), or other grid conditions (e.g. $[11,12])$.

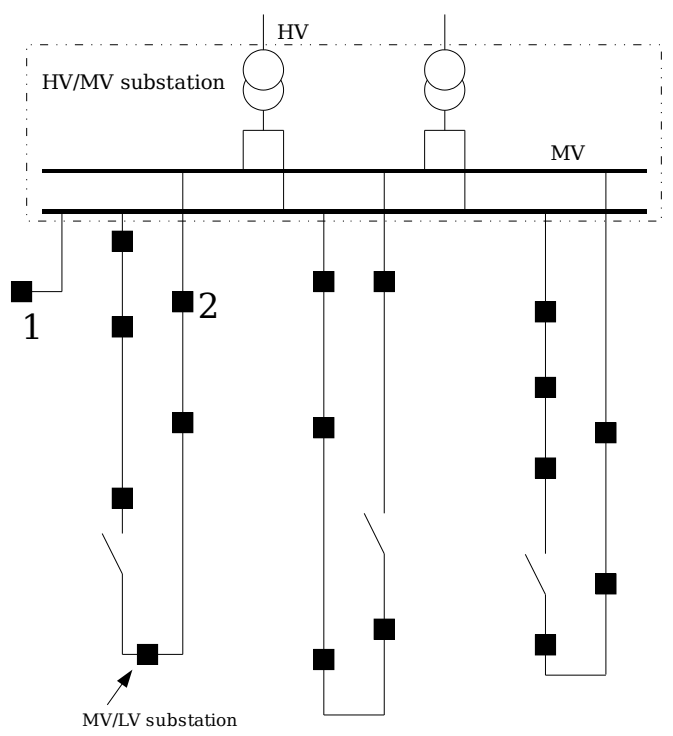

Figure 3: Simplified scheme of a typical MS distribution grid (protection devices are not shown)

Voltage dips originate from faults on nearby branches. The number of voltage dips a site encounters per year and their distribution is dependent on the grid topology and the grid impedances [7].

\section{On-site reliability}

The on-site reliability is similar to the reliability of the distribution (and transmission) grid, except for the fact that a customer has control over the on-site grid. $\mathrm{He}$ is therefore able to modify this parameters, e.g.by installing a redundant transformer and thus influencing the number of interruptions reaching the sensitive equipment. The on-site reliability parameters can be calculated using basic reliability theory. When assuming an exponential distribution, the actual calculations can be done using stochastic probability or Markov chains of the first order. Using this last method, the reliability indices for the series connection $\left(\lambda_{s}\right.$ and $\left.M T T R_{s}\right)$ and parallel connection $\left(\lambda_{p}\right.$ and $\left.M T T R_{p}\right)$ of two components (index 1 and 2) can be calculated as follows:

$$
\begin{gathered}
\lambda_{s}=\frac{\mu_{1} \cdot \mu_{2} \cdot\left(\lambda_{1}+\lambda_{2}\right)}{\left(\lambda_{1}+\mu_{1}\right) \cdot\left(\lambda_{2}+\mu_{2}\right)}=\frac{1}{M T B F_{s}} \\
\mu_{s}=\frac{\mu_{1} \cdot \mu_{2} \cdot\left(\lambda_{1}+\lambda_{2}\right)}{\left(\lambda_{1}+\mu_{1}\right) \cdot\left(\lambda_{2}+\mu_{2}\right)-\mu_{1} \cdot \mu_{2}}=\frac{1}{M T T R_{s}}
\end{gathered}
$$

$$
\begin{gathered}
\lambda_{p}=\frac{\lambda_{1} \cdot \lambda_{2} \cdot\left(\mu_{1}+\mu_{2}\right)}{\left(\lambda_{1}+\mu_{1}\right) \cdot\left(\lambda_{2}+\mu_{2}\right)}=\frac{1}{M T B F_{p}} \\
\mu_{p}=\mu_{1}+\mu_{2}=\frac{1}{M T T R_{p}}
\end{gathered}
$$

Where $\mu$ is the repair rate, which is the inverse of the MTTR. Using these four simple formulae, the reliability at the terminals of the sensitive installation can be determined. The reliability data of the components is available with the manufacturer or can be found in the literature [13].

\section{Mitigation methods and their reliability improve- ment}

It lies beyond the scope of this work to describe all the possible mitigation methods, but some general observations are made. The most common mitigation methods are those who supply the sensitive equipment through an alternative supply during a voltage dip or interruption. This alternative supply can be a grid supplied through a generator or an additional, redundant connection to the electricity grid. The transition from the faulty energy supply to the redundant connection is not immediate, and there will be a process interruption if the voltage tolerance is smaller than the caused interruption duration at the terminals of the sensitive equipment (fig. 4).

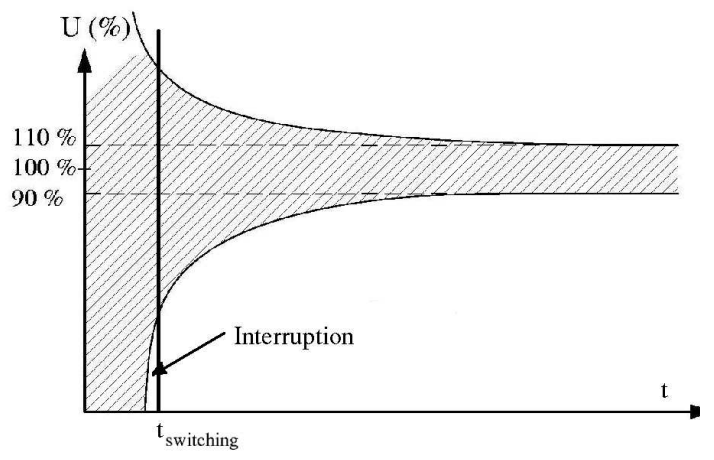

Figure 4: Possible interruption due to switching from power supply.

The alternative energy supply can also come from a local energy storage device such as is the case for static and flywheel UPSs. The dynamic output of these devices is standardized in IEC 62040-3 [14]. In the case of a switching to a stored energy source, the protection duration is limited according to the amount of stored energy. If a mitigation method with a local energy storage is inserted in the grid, the formulas from (1) can no longer be used to take this device into account. In this case the reliability at the output of a static UPS with bypass can be calculated in the following manner [15]:

- every event shorter then the autonomy is mitigated, under the condition the UPS works properly. This autonomy depends on the load of the UPS;

- every event longer than the autonomy, will cause the UPS to switch supply to bypass after the autonomy (bypass reliability); 
- if the UPS is out of order, the supply is taken from the bypass, and the sensitive device experiences the bypass reliability.

The availability of the mitigation method can be calculated with the following formula:

$$
\text { availability }=\frac{M T B F}{M T B F+M T T R}
$$

Assuming an exponential distribution of the power interruption duration, the probability of a process interruption caused by a voltage interruption which is longer than the time the mitigation device is able to protect the load is:

$$
p\left(t>t_{\text {aut }}\right)=e^{-\frac{t_{\text {aut }}}{M T T R} \cdot \frac{P_{R}}{P}}
$$

where:

$$
\begin{cases}t_{\text {aut }} & \text { autonomy with rated load; } \\ \text { MTTR } & \text { Mean Time To Repair; } \\ r & \text { rated power; } \\ P & \text { consumed power. }\end{cases}
$$

Certain applications are especially designed to mitigate voltage dips and do not protect against interruptions. Examples of these devices are Dynamic Voltage Restorers (DVR) and Statcom devices. The effect of these mitigation methods is an enlargement of the voltage tolerance area. The improvement in reliability can be calculated as the number of voltage dips in the extension of the voltage tolerance characteristics. A distinction must be made between mitigation devices that can extend the voltage characteristics with a certain value and devices that extend the voltage tolerance until a certain value is reached (independent of the initial voltage characteristics) [16]. This is important when calculating the actual number of process interruptions after the installation of mitigation equipment.

Another form of mitigation is the reduction of the number of occurring events by changing the grid infrastructure. For on-site changes, this can be done by adding redundancy of components, providing redundant supply and/or making the connection to a higher short circuit level. The feasibility of these solutions is very case dependent and a thorough analysis is needed. For grid improvements or restructuring of the public electricity grid, it is up to the grid maintainer to make the improvements. With the co-operation of the electricity consumers, this can lead to a reliability based, cost effective investment policy $[10,17]$.

\section{E. Conclusion}

If sufficient reliable data is used, the expected number of interruptions the critical application experiences, can be calculated. However, the reliability data is not always precisely known, especially the net reliability is based on historical data and may change in time.

\section{Interruption cost}

Next to the number of process interruptions is the cost of these interruptions to be determined when calculating the optimal investment. This interruption cost is in most cases unknown and dependent on several parameters:

- point in time of the event (day - night, winter summer,...);

- economic situation;

- duration of the event;

- announced or unannounced event;

- availability of other energy sources;

- weather conditions;

- damage caused to the installation;

-...

As an example the variation of the interruption cost as a function of the interruption duration is treated. Fig. 5 displays four different cost scenarios as a function of interruption duration:

1) interruption costs for an installation with a high initial cost and relative low variable costs, for instance the paper industry;

2) installation with no initial costs and a high variable cost after a certain time, for instance a poultry farm: after about $30 \mathrm{~min}$ the animals will die of suffocation because of a lack of ventilation;

3) non-linear curve with limited initial costs and high costs if the electricity is not restored before a certain time. Afterwards the costs rises again slowly. An application of with such a curve is a static UPS protected data centre;

4) typical curve for the sale of non-perishable goods: low initial cost as sales will be postponed, on the long term the costs rise because the loss of client confidence (e.g. railway companies).

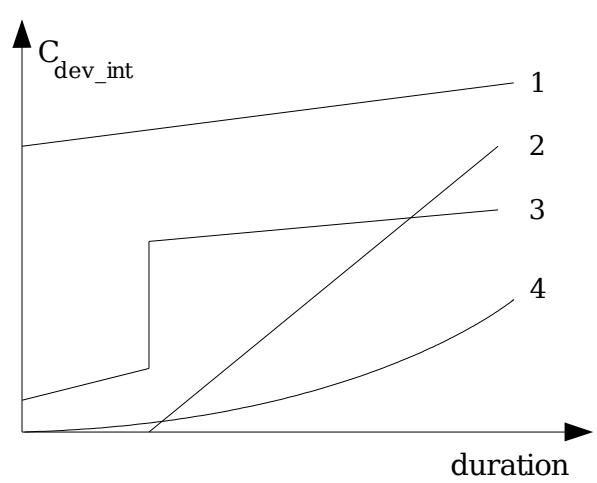

Figure 5: The interruption cost of a device as a function of interruption duration

\section{Theoretical method}

\section{A. Optimal solution}

The theoretical method uses traditional economic methods to calculate the optimal investment. This optimal 
solution is that solution with a minimal sum of interruption cost and mitigation cost [18]. Equation (6) symbolizes this optimization:

$$
\operatorname{Min}\left\{C_{\text {Total }}=C_{\text {mitigation }}+C_{\text {interruption }}\right\}
$$

This can be reformulated as maximizing the return of the reduction in interruptions method reduced with the additional cost of mitigating:

$$
\operatorname{Max}\left\{\text { return }=f_{n} \cdot C_{1} \text { interruption }-C_{\text {mitigation }}\right\}
$$

with $f_{n}$ the number of avoided process interruptions.

\section{B. Net-Present-Value method}

Over the years, several of these economic cost-benefit methods are developed. Of these, the Net-PresentValue method (NPV), the pay-back method, the internal rate of return and profitability index are most known. Since the NPV method is widely accepted as the appropriate method to calculate the profitability of investment possibilities [19], it is this method that is described here, but analog considerations can be made using other methods.

NPV: The present value of a single investment's future net cash flow minus the initial investment. If the NPV is positive, the investment should be made (unless an even better investment exists), otherwise it should not.

The use of the NPV method to evaluate mitigation methods is represented by following formula:

$$
N P V=-C_{0}+\sum_{n=0}^{n_{\text {tot }}} \frac{f_{n} \cdot C_{\text {dev_int }}-C_{\text {operating }}}{(1+r)^{n}}
$$

where:

$$
\begin{cases}C_{0} & \text { investment cost; } \\ C_{\text {dev_int }} & \text { cost per process interruption; } \\ f_{n} \cdot C_{\text {dev_int }} & \text { avoided economic damage, profit; } \\ C_{\text {operating }} & \text { yearly operating costs, including } \\ & \text { maintenance; } \\ r & \text { capitalisation rate; } \\ n_{\text {tot }} & \text { lifetime of the investment. }\end{cases}
$$

The operating costs include maintenance costs, planned replacement of parts (such as batteries), efficiency losses, cooling losses (e.g. air-conditioning in the battery chamber) and other services. These costs are well defined and easily brought into account.

Some variables of the interruption cost 3 can be accounted for and used when calculating the NPV, but the determination of the correct distribution and the influence longs for a great amount of measurement data. However, and fortunately, voltage interruptions and dips only occur a limited times per year so the measurements take a lot of time. Other cost, such as social costs, simply can not be brought into account. In practice, the determination of the cost of an interruption is difficult, and even somewhat arbitrary.

\section{Application of the theoretical method}

The uncertainty in the many variables, especially the interruption cost and grid reliability, and the large availability in mitigation methods make this method unusable for most users. At most they have rough estimate of a process interruption cost. Another important issue is the decision taking procedure. In most cases an investment has to be approved the management who often are not technically oriented engineers, or certainly not reliability or power quality experts. Therefore, this method is rarely used, solely in case of a demand for very high availability.

\section{Currently used methods in the indus- try}

\section{A. Introduction}

There are several industry branches that are known to be sensitive to voltage dips and interruptions: telecommunications, banking and insurance, hospitals, chemical and pharmaceutical factories and all computer related industries. Within the framework of this research, a number of companies from these industries were surveyed. Also some producers and installers of mitigation equipment were contacted. Some general conclusions concerning the economic optimization are presented here.

\section{B. Demand for reliability}

The cost of an interruption of the critical device or installation is in most cases not known, and therefore a maximum allowed number of interruptions (or a minimum unavailability) is demanded. This directly excludes a lot of 'rather cheap' mitigation methods from the calculations, although these methods might have led to a economic solution, though with more process interruptions.

\section{Divide in groups and use standardized solutions}

Most companies tend to divide their appliances into several groups of criticality, and use standard solutions for each group. This can be economically beneficial, especially with large numbers of equal devices. This also causes shorter repair times when an in-stock replacement is available, which improves the overall availability of the installation.

\section{Brand loyalty}

A third item is that most companies prefer 'known' brand names, and tend to stick to the same brand. This ensures more or less the same operation controls for different devices. An important number of faults, namely operator faults, can be reduced this way, so the expected availability is higher.

The service a producer or installer delivers is also important. There is a tendency to out-source all of the 
maintenance and repair services and often 24-hour availability for these services is demanded.

\section{E. Traditional choices}

The applied mitigation methods are rather 'classic' installations: redundant devices, static UPSs, rotary UPSs and diesel generators. Most new devices (mainly power electronic converters) are not even considered, or simply unknown to the customers.

\section{F. Computer protection}

A large section of the mitigation devices is used to protect computers and other IT devices. Two remarkable observations can be made concerning the applied mitigation methods (mostly static UPSs):

- most of the mitigation equipment has a very low maximum loading level $(25-35 \%$ maximum load is not abnormal), this while most static UPSs have an efficiency of only $85-90 \%$ in this power range. A reason for this is the gathering of the power consumption data of the expected load: often the rated power of the power supplies is used, while these are only valid at full load (which is rare) [20];

- the mitigation equipment is often placed in a redundant configuration $(n-1)$. Main argument is that 'the IT-department does not allow a direct connection with the electricity grid, not even during maintenance or fault'. No cost, nor reliability study is performed. One can question the total reliability improvement of the entire installation by adding an extra electrical mitigation device since also computer hardware and software reliability have to be taken into account.

\section{G. Protection of large power installations}

Complete protection of large industrial installations against voltage dips and interruptions, such as encountered in process chemistry, is difficult and expensive. The main objective is to maintain safety and, if possible, limit the damage caused by process interruptions. This includes avoiding damaged equipment and safe restart of the installation as soon as possible. The used methods include independent redundant power supply (up to transmission level), process control designed for protection and energy buffering (UPS) for control equipment.

\section{H. Conclusions}

System reliability is seen as a result of the correct use of some rules of thumb and not a design consideration. If reliability is calculated, it is to obtain a desired level of reliability/availability and economic considerations are not made.

Technical and economic differences between the different mitigation methods make comparison difficult, and choices are being made on other criteria, not always leading to a techno-economic optimum. In many cases the installation is over-protected and over-powered.

\section{Techno-economic optimization}

\section{A. Proposed method}

Since both the theoretical optimization and the practice have their drawbacks, a method is proposed to compare different mitigation methods, using available data, in order to find an optimal solution. The theoretical method asks to place a value to the interruption costs, but this is in most cases very difficult ??. When changing the optimization question from a value for the interruption cost to the question 'how much am I willing to pay to avoid a process interruption', the reliability is regarded as a techno-economic value, and no longer as a mere cost. It allows us to compare methods without prejudice. It avoids the problem of demanding a maximum number of process interruptions (minimum availability) (5-B.).

The calculations are entirely based on the theoretical method, but the interruption cost is treated as a variable and the NPV (see eq. (6)) is calculated as a function of this interruption cost, with constant grid reliability. This is done for every proposed mitigation method. The data that is used for this comparison can be obtained from the grid reliability data and the quotations. The results lead to intervals of optimal solutions for the given grid reliability. These ranges in interruption cost can be can be used in the decision process because rough estimates of the interruption costs are available. This method gives the interruption cost as a result, not as a variable. Fig. 6 shows a typical example for three mitigation devices, the device with the highest NPV is the most economic. The three devices give four possible optimal solutions: no mitigation in zone $\mathrm{A}$, the long dashed method in zone $\mathrm{B}$, the method presented by the continuous line in zone $\mathrm{C}$ and the method according to the line with the short dashes for high interruption costs.

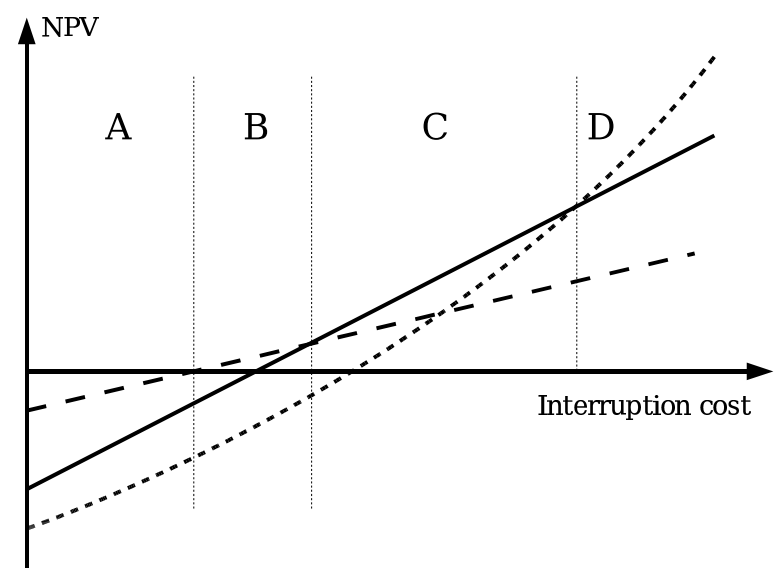

Figure 6: The calculation of the NPV with variable interruption costs and constant grid reliability leads to intervals of interruption cost, where one optimal solution exists.

\section{B. Sensitivity of the reliability}

For this method to be valid, the influence of possible fluctuation on the reliability indices has to be small. 
Therefore the reliability data have to be known in with a small tolerance or the sensitivity to fluctuations of these reliability indices has to be small.

To illustrate this the following example is simulated: A data center with a rated power consumption of $240 \mathrm{kVA}$ (@ $\cos \phi=0,8)$ is to be protected against voltage dips and fluctuations. The installation has to be available '24/7', (but a yearly planned maintenance shutdown is possible). The capitalization rate within the firm is $10 \%$ and the expected lifetime of the project is 15 year.

After the nescessary measurements and reliability calculations, the expectations for the reliability indices at the terminals of the sensitive machine are the following: $\lambda=1$ interruption/year $(\mathrm{MTBF}=8760 \mathrm{~h})$, $M T T R=100 \mathrm{~min}$ and $\bar{\delta}=16$ dips/year. These reliability data have an accuracy of $\pm 15 \%$. The voltage tolerance is equal to the one proposed by the ITIC [5], and measurements have shown that $31,8 \%$ of the voltage dips are outside this curve.

Three quotations are considered:

a) standard $300 \mathrm{kVA}$ static UPS with a an autonomy of $15 \mathrm{~min}$

b) two redundant static UPSs of $300 \mathrm{kVA}$ with each an autonomy of 15 min;

c) flywheel $250 \mathrm{kVA}$ UPS with autonomy $17,6 \mathrm{~s}$.

The calculations, performed for these three solutions, results in a graph similar to fig. 6. The resulting intervals are given in 2 .

Table 2: Interruption cost intervals

\begin{tabular}{lcc}
\hline Optimal investment & \multicolumn{2}{c}{$\begin{array}{c}\text { Interruption } \\
\text { cost }(€ / \text { int. })\end{array}$} \\
\hline No investment & 0 & 4218 \\
Investment c: flywheel UPS & 4218 & 14125 \\
Investment b: single UPS & 14125 & 38881 \\
Investment c: redundant UPSs & 38881 & $\infty$ \\
\hline
\end{tabular}

The sensitivity (S) for changing MTBF, MTTR and $\bar{\delta}$ can be seen from fig. 7. This figure shows the areas where a certain mitigation method is optimal, as a function of one changing reliability index and the interruption cost. Also the expected value of the reliability and the tollerance of $\pm 15 \%$ are shown. The sensitivity to the changing of a reliability can be written as follows (7):

$$
S_{x}=\frac{\partial \Delta C_{i n t}}{\partial x}
$$

with $S_{x}$ the sensitivity to reliability index $x$ of the interruption cost interval $\left(\Delta C_{i n t}\right)$.

It can be concluded that the sensitivity to voltage dips is very low when the annual number of voltage dips exceeds five. Variations of $M T B F$ and $M T T R$ have a bigger influence on the interruption cost interval, but
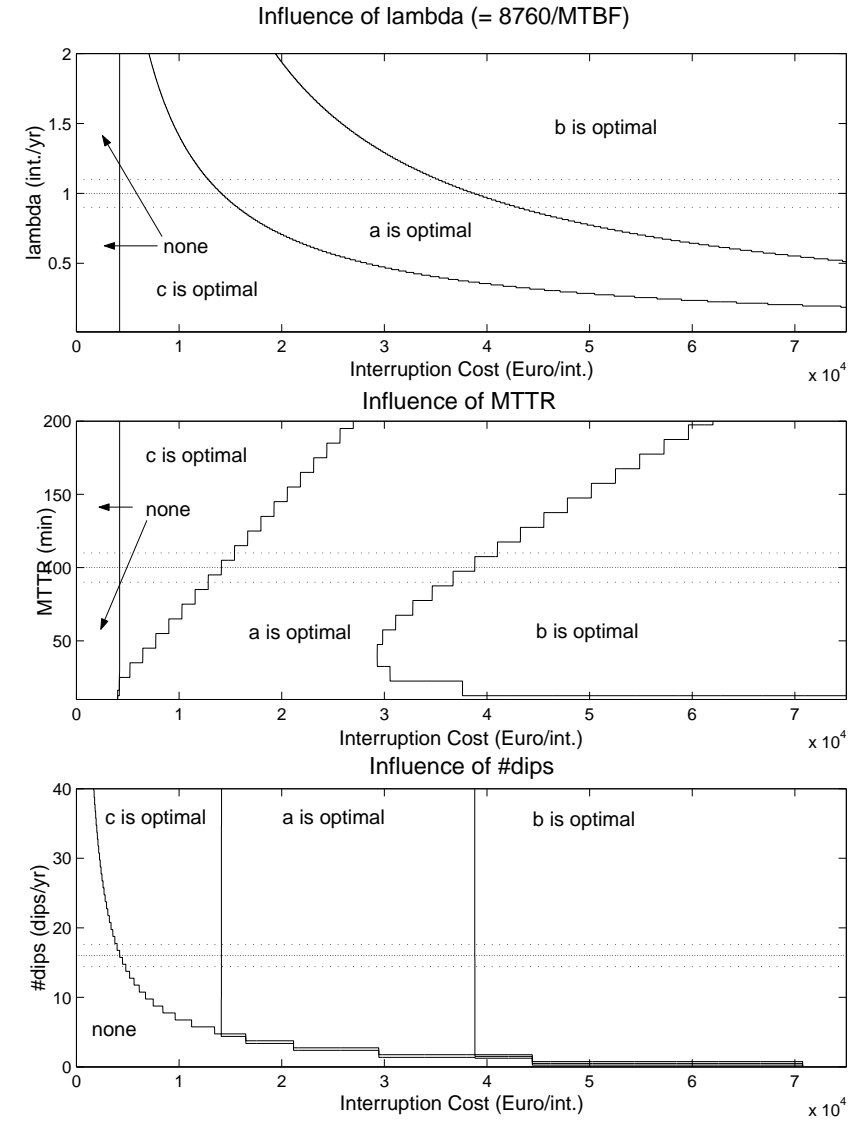

Figure 7: Sensitivity to the different reliability indices.

it is still limited. We can conclude from fig. 7 that the results of table 2 are sufficiently accurate and can be accepted.

\section{Future work}

If the sensitivity to the reliability indices is significant, an optimal solution can be found by using optimization techniques over the area $\left[\Delta_{\lambda}, \Delta_{M T T R}, \Delta \bar{\delta}\right.$ and $\left.\Delta C_{i n t}\right]$.

\section{General conclusions}

Though there is a theoretical method available to select the optimal voltage dip mitigation method, it is not useful because of the high number of unknown variables, of which the interruption cost is the most important. The solutions used in the industry are not based on a technoeconomic optimization, but use the rule of thumb or demand a minimum level of reliability. This leads to situations where the critical device is over-protected and the protection is more expensive than the faults they prevent. A solution is provided using the available data and divides the interruption cost in intervals in which a certain mitigation method is the optimal investment. These cost intervals make it possible to choose the correct mitigation, since in most cases a rough estimate of the interruption cost can be made. 


\section{References}

[1] W. Sweet, "The blackout of 2003," IEEE Spectrum online, 2003, http://www.spectrum.ieee.org/ WEBONLY/special/aug03/black03.html.

[2] UCTE, "Interim report of the investigation committee on the 28 september 2003 blackout in Italy," Oct. 2003. [Online]. Available: http://www.ucte.org/pdf/Publications/2003/ UCTE-IC-InterimReport-2003102\%7.zip

[3] PRIMEN, The Cost of Power Disturbances to Industrial $\&$ Digital Economy Companies, CEIDS, Ed. Palo Alto, USA: EPRI, 2001.

[4] M. Bollen, Understanding Power Quality Problems, Voltage sags and interruptions. Piscataway, New Jersey: IEEE Press, 2000.

[5] Information Technology Industry Council (ITI), "ITI (CBEMA) curve application note," p. 3, 2000. [Online]. Available: http://www.itic.org/technical/iticurv.pdf

[6] D. Van Hertem, "Techno-economische optimalisatie van maatregelen tegen spanningsdips en -onderbrekingen," Master's thesis, Katholieke Universiteit Leuven, June 2003.

[7] M. Didden, "Techno-conomic analysis of methods to reduce damage due to voltage dips," Ph.D. dissertation, Katholieke Universiteit Leuven, Dec. 2003.

[8] D. Van Hertem, M. Didden, J. Driesen, and R. Belmans, "Optimal mitigation of voltage dips and interruptions," in Proc. IEEE Young Researchers Symposium in Electrical Power Engineering, Delft, The Netherlands, Mar. 2004.

[9] M. Dussart, J. Cooreman, C. Pirine, and S. Magnus, "Unavailability reduction and its cost," in Proc. 17th International Conference on Elektricity Distribution, Barcelona, Spain.

[10] A. Chowdhury and D. Koval, "Deregulated transmission system reliability planning criteria based on historical equipment performance data," IEEE Transactions on Industry Applications, vol. 37, no. 1, pp. 204-211, 2001 .

[11] D. O. Koval, J. Leonard, and Z. J. Licsko, "Power quality of small rural industries," IEEE Transactions on Industrie Applications, vol. 29, no. 4, pp. 696-700, 1993.

[12] A. Friday, C. Watts, G. Stott, and I. Boira-Segarra, "Improving quality of service - information and incentives in the GB electricity distribution industry," in Proc. 17th International Conference on Electricity Distribution, CIRED. Barcelona, Spain: 1, May 2003, p. 6 .

[13] A. Montebaur, Zuverlässigkeitsanalysen industrieller Elektrizitätsversorgungsnetze unter Einschlußder Productionsprozesse. Aachen: Institut fur Elektrische Anlagen und Energiewirtschaft, 1996, no. 42.

[14] International Elektrotechnical Commission (IEC), International standard IEC 62040-3; Uninteruptible power systems (ups) - Part 3: Method of specifying the performance and test requirements. IEC, 1999.

[15] APC. (2002) Effect of UPS on system availability. American Power Conversion. [Online]. Available: http://www.limbtec.co.uk/documents/ whitepapers/WhitePaper24.pdf
[16] M. Didden, K. Stockman, R. Belmans, and W. D'haeseleer, "Considerations for choosing the appropiate voltage sag mitigation device," in Proc. 17th International Conference on Elektricity Distribution, Barcelona, Spain.

[17] A. Chowdhury and D. Koval, "Application of customer interruption cost in transmission network reliability planning," IEEE Transactions on Industry Applications, vol. 37, no. 6, pp. 1590-1596, 2001.

[18] M. McGranaghan and B. Roettger, "Economic evaluation of power quality," IEEE Power Engineering Review, vol. 22, no. 2, pp. 8-12, 2002.

[19] R. Brealey and S. Myers, Principles of corporate finance, 6th ed. McGraw-Hill, 1999, no. ISBN 0-07709565-0.

[20] APC, "Avoiding costs from oversizing data center and network room infrastructure," American Power Conversion, 2004. [Online]. Available: ftp://www. apcmedia.com/salestools/SADE-5TNNEP_R4_EN.pdf 